\title{
Risk factors associated with tick infestations on equids in Khyber Pakhtunkhwa, Pakistan, with notes on Rickettsia massiliae detection
}

\author{
Abid Ali ${ }^{1 *}$, Hafsa Zahid ${ }^{1}$, Ismail Zeb ${ }^{1}$, Muhammad Tufail', Sulaiman Khan ${ }^{1}$, Muhammad Haroon',

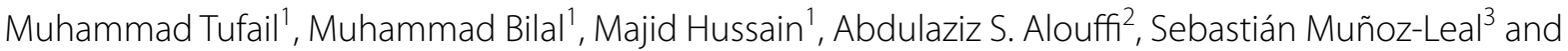 \\ Marcelo B. Labruna ${ }^{4}$
}

\begin{abstract}
Background: Studies on ticks infesting equids are lacking in various parts of the world, including Khyber Pakhtunkhwa (KP), Pakistan. The aim of this study was to investigate the diversity of ticks infesting equids, associated risk factors and rickettsial detection in ticks from equids in $\mathrm{KP}$.

Methods: Inspection of 404 equid hosts from November 2018 to October 2019 resulted in the collection of 550 ticks. Data on tick-associated risk factors were collected from equid owners by means of a questionnaire. After morphological identification, partial DNA sequences of the tick mitochondrial 16S rRNA gene were used for taxonomic confirmation of species. Partial sequences of the gltA and ompA genes were used for Rickettsia detection in ticks.

Results: A total of 550 tick specimens were collected on 324 (80.2\%) of the equids inspected, of which 161 were horses (50\%), 145 (45\%) were donkeys and 18 were mules (5\%). The ticks were identified as belonging to the following five species: Rhipicephalus microplus (341 specimens, 62\% of the total ticks), Rh. haemaphysaloides (126, 23\%), Rh. turanicus (39, 7\%), Rh. sanguineus (s.l.) (33,6\%) and Hyalomma anatolicum (11, 2\%). The most prevalent tick life stage was adult females $(279,51 \%)$ followed by adult males $(186,34 \%)$ and nymphs $(85,15 \%)$. Higher tick infestations were observed on male equids (relative risk [RR] $0.7432, P<0.0005$ ) and adult equids (RR 1.268, $P<0.0020$ ). Ticks were frequently attached to the axial region of horses $(55,21 \%)$, sternum of donkeys $(44,21 \%)$ and belly of mules $(19,23 \%)$ $(P<0.04)$. Temporal patterns of tick infestation in association with temperature and humidity were highly significant $(P<0.05)$. Risk factors, such as animal housing $(P<0.0003)$, living management $(P<0.006)$, grazing type $(P<0.01)$ and location in hilly areas $(P<0.02)$, significantly enhanced the chances for tick infestation. Tick species analyzed in this study were phylogenetically related to species from Afghanistan, China, South Africa and Taiwan. Partial sequences of the gltA and ompA genes obtained from Rh. microplus and Rh. haemaphysaloides were $100 \%$ identical to the spotted fever group pathogen Rickettsia massiliae.
\end{abstract}

Conclusions: Equids exposed to significant risk factors were infected by one or more of at least five tick species in KP, Pakistan, and some of the ticks harbored the human pathogen R. massiliae.

Keywords: Equids, Pakistan, Rickettsia, Risk factors, Ticks

*Correspondence: uop_ali@yahoo.com

1 Department of Zoology, Abdul Wali Khan University Mardan, Khyber Pakhtunkhwa, Pakistan

Full list of author information is available at the end of the article

\section{Background}

Ticks cause substantial economic losses in various communities around the world, but especially in lowincome livestock holders in tropical and subtropical

c) The Author(s) 2021. This article is licensed under a Creative Commons Attribution 4.0 International License, which permits use, sharing, adaptation, distribution and reproduction in any medium or format, as long as you give appropriate credit to the original author(s) and the source, provide a link to the Creative Commons licence, and indicate if changes were made. The images or other third party material in this article are included in the article's Creative Commons licence, unless indicated otherwise in a credit line to the material. If material is not included in the article's Creative Commons licence and your intended use is not permitted by statutory regulation or exceeds the permitted use, you will need to obtain permission directly from the copyright holder. To view a copy of this licence, visit http://creativecommons.org/licenses/by/4.0/. The Creative Commons Public Domain Dedication waiver (http://creativecommons.org/publicdomain/zero/1.0/) applies to the data made available in this article, unless otherwise stated in a credit line to the data. 
regions, where approximately $80 \%$ of the world's cattle population is at risk of infestation [1]. These hematophagous ectoparasites play a major role in the transmission of pathogens, including bacteria, such as intracellular coccobacilli of the genus Rickettsia, and several protozoans and viruses that cause disease and are a threat to human and veterinary health [2-4]. Only $10 \%$ of tick species have been identified as carriers of pathogens; the remaining species require further research to determine whether they are vectors of disease.

Both the persistence of various life stages of ticks and their distribution depend mainly on such factors as habitat, climatic conditions, host availability and anthropogenic activities. Both biotic (vegetation structure, host availability and management) and abiotic (rainfall regimen, temperature range) factors are most likely to influence tick distributions on a global scale [5-7]. The potential impacts of climate change and transboundary movements of humans and animals on the distribution of ticks have been widely studied $[8,9]$. Understanding the niche of a tick species is a complex exercise due to the multiple variables operating on the different stages of the tick life-cycle, including regulation of the patterns of tick and host abundance and their spatial encounters [10]. Some tick species exhibit ecological flexibility and adapt easily to changing climate and novel habitats $[10$, 11]. Efforts have been made at global, regional and local scales to characterize the major environmental factors influencing tick distributions using statistical models and correlative approaches [12]. The documentation of risk factors associated with tick distribution contributes to the design of cost-effective control measures.

Livestock activities are an integral part of Pakistan's economy and the backbone of rural income, as more than $70 \%$ of the population live in rural areas [13]. According to the Agricultural Census Organization, the total equid population in Pakistan was 4.8 million in 2006, which rose to 5.5 million as per the census report in 2012-2013. The Pakistan Economic Survey 2018-2019 reported that the horse population was 0.4 million, donkey population was 5.4 million and mule population was 0.2 million (https://www.thenews.com.pk/print/482965-donke ys-population-increased). Khyber Pakhtunkhwa (KP) is a mountainous region of Pakistan that lacks sufficient access to transport infrastructure. Consequently, equids play important roles in providing transportation, but also in farming, pumping water and milling activities in elevated areas. Equids are also used in fairs and games, such as horse races and polo festivals. However, despite their economic importance, the welfare of equids has received far less attention than that given to other animals in Pakistan.
Equids are frequently employed in outdoor activities and are therefore exposed to tick infestations [14, 15]. Previous studies conducted in Pakistan were mostly confined to domestic animals but excluded equids, thereby limiting our understanding of the prevalence of and associated risk factors for tick infestations on these animals [13, 16, 17]. In addition, although Pakistan's climatic conditions are suitable for the survival of tick species that parasitize domestic animals, investigations on the frequency and distribution of ticks infesting equids are lacking, as are data on Rickettsia associated to equid ticks that are pathogenic to humans. The present study was designed to investigate the diversity of ticks, assess the presence of Rickettsia and estimate the risk factors associated with ticks infesting equids in KP.

\section{Methods}

Study area

We selected nine districts in northern, southern and central KP (northwestern geographic state of Pakistan, previously known as the North-West Frontier Province) as study areas: Charsadda $\left(71.669079^{\circ} \mathrm{E}, 34.209086^{\circ} \mathrm{N}\right)$, Mardan $\quad\left(72.079179^{\circ} \mathrm{E}, \quad 34.161767^{\circ} \mathrm{N}\right), \quad$ Nowshera $\left(72.005571^{\circ} \mathrm{E}, \quad 33.988264^{\circ} \mathrm{N}\right)$, Peshawar $\left(72.378867^{\circ} \mathrm{E}\right.$, $\left.34.093417^{\circ} \mathrm{N}\right)$, Buner $\left(72.484021^{\circ} \mathrm{E}, \quad 34.450940^{\circ} \mathrm{N}\right)$, Malakand $\left(71.863614^{\circ} \mathrm{E}, \quad 34.519290^{\circ} \mathrm{N}\right)$, Upper Dir $\left(71.995056^{\circ} \mathrm{E}, \quad 35.066089^{\circ} \mathrm{N}\right), \quad$ Swabi $\left(72.394640^{\circ} \mathrm{E}\right.$, $\left.34.119706^{\circ} \mathrm{N}\right)$ and Bajaur $\left(71.621760^{\circ} \mathrm{E}, 34.634959^{\circ} \mathrm{N}\right)$. Based on access, nine regions of each of these districts were selected for tick sampling. A global positioning system (GPS) was used to obtain the geographic coordinates data and loaded onto a Microsoft Excel (Microsoft Corp., Redmond, WA, USA) spreadsheet to develop a distribution map for the study area using ArcGIS 10.3.1 (Fig. 1).

\section{Ethical consent and information collection}

Ethical consent was obtained from the advanced studies and research board of the Abdul Wali Khan University Mardan. Oral/written consent was obtained from the owner of equids for the collection of ticks. A questionnaire was provided to equid holders that assisted in collection of data such as: host-related information (gender and age), eco-geography and herd management.

\section{Tick collection and morphological identification}

Ticks were collected between November 2018 and October 2019 from horses, donkeys and mules at different sites (villages, towns) in tehsils (i. e. administrative divisions) within the nine districts (Fig. 1). Two visits per month were made to each area, and information related to climate was retrieved. In infested areas, ticks of all stages were removed from the base of the tail, ears, perianal area, sternum, scrotal and belly, using forceps without 


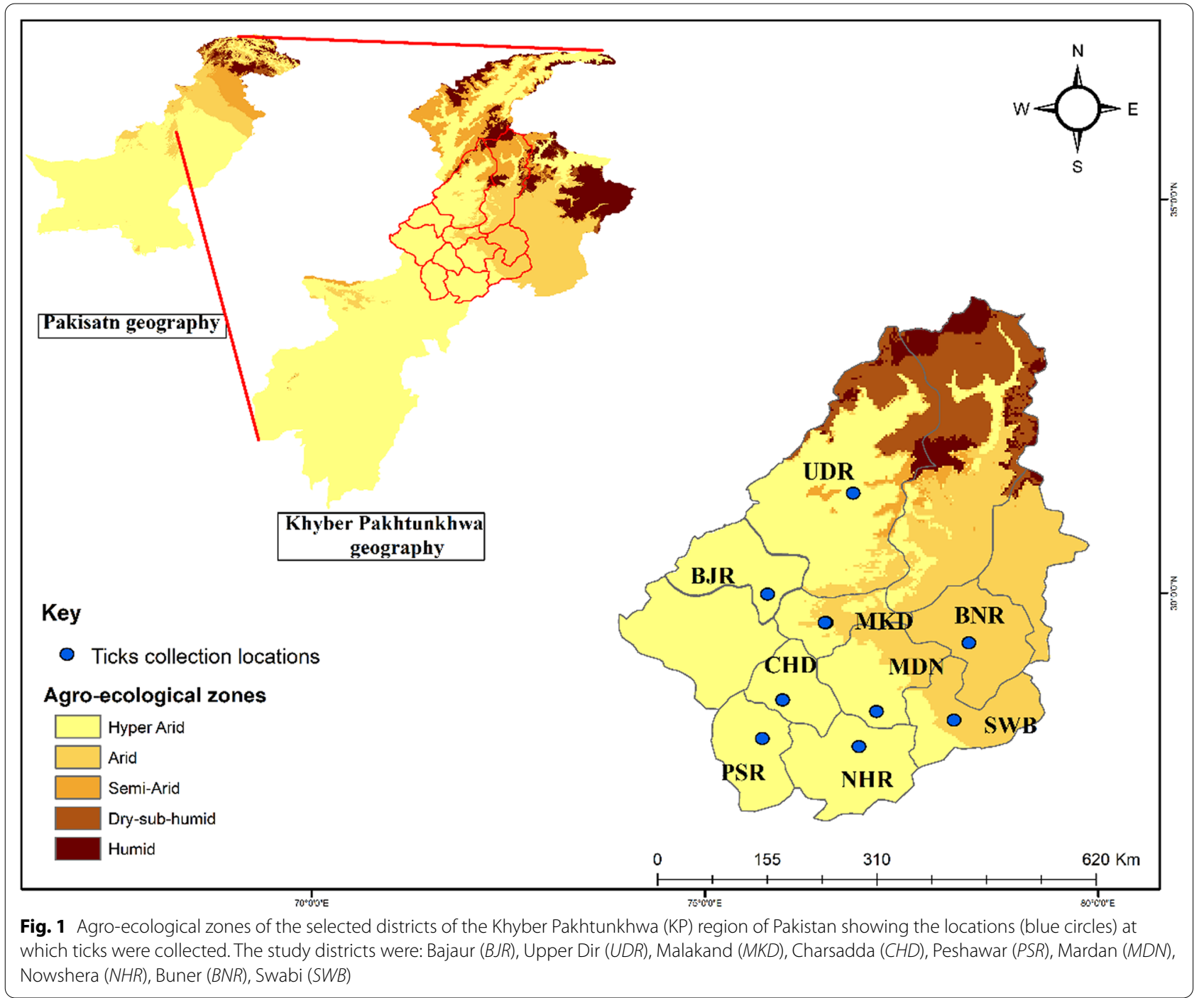

damaging the morphological features of the ticks. The collected ticks were placed in vials containing $100 \%$ ethanol and brought to the laboratory for identification.

Collected ticks were identified morphologically under a StereoZoom microscope (HT StereoZoom) and following taxonomic keys $[18,19]$. The specimens were preserved in $100 \%$ ethanol for later molecular analysis.

\section{DNA extraction and PCR}

Tick specimens were rinsed in distilled water and $70 \%$ ethanol and dried prior to DNA extraction [17]. Specimens were cut into pieces with a sterilized scalpel inside Eppendorf tubes. Genomic DNA of 91 randomly selected ticks was extracted using the phenol-chloroform method $[20,21]$. Sterile conditions were maintained throughout the process. The concentration of DNA in each sample was quantified using a spectrometer (Thermo Fisher
Scientific, Waltham, MA, USA). The extracted DNA was stored at $-20^{\circ} \mathrm{C}$.

Conventional PCR targeting a fragment (approx. 460 bp) of the tick mitochondrial 16S rRNA gene was carried out as previously described [22] to verify successful extractions (Table 1). A real-time PCR (StepOne; Applied Biosystems, Thermo Fisher Scientific, Waltham, MA USA) was performed to detect a short fragment (147 bp) of the Rickettsia citrate synthase-encoding gene (gltA) using primers CS-5 and CS- 6 and an internal fluorogenic probe (6-carboxyfluorescein [6-FAM]) [2]. Positive samples were subjected to two conventional PCR assays, one to obtain a larger sequence (401 bp) of the rickettsial gltA gene, using primers CS-78 and CS-323 [2], and the other to amplify a 532-bp fragment of the rickettsial outer membrane protein A $(o m p A)$ gene [23]. Conventional PCR reactions consisted of a $25-\mu \mathrm{l} \operatorname{mix}(2 \mu \mathrm{l}$ 
Table 1 List of primers used for the amplification of target genes of ticks and Rickettsia spp.

\begin{tabular}{|c|c|c|c|c|}
\hline Organism/gene & Primer & Primers sequences $\left(5^{\prime}-3^{\prime}\right)$ & Product size (bp) & References \\
\hline \multirow[t]{2}{*}{ Tick 16S rRNA } & $16 S+1$ & CCGGTCTGAACTCAGATCAAGT & \multirow[t]{2}{*}{460} & \multirow[t]{2}{*}{ [22] } \\
\hline & $16 S-1$ & GCTCAATGATTTTTTAAATTGCTG & & \\
\hline \multirow[t]{2}{*}{ Rickettsia spp./gltA } & $C S-5^{a}$ & GAGAGAAAATTATATCCAAATGTTGAT & \multirow[t]{2}{*}{147} & \multirow[t]{2}{*}[2]{} \\
\hline & $C S-6^{a}$ & AGGGTCTTCGTGCATTTCTT & & \\
\hline \multirow[t]{2}{*}{ Rickettsia spp./gltA } & CS-78 & GCAAGTATCGGTGAGGATGTAAT & \multirow[t]{2}{*}{401} & \multirow[t]{2}{*}[2]{} \\
\hline & CS-323 & GCTTCCTAAAATTCAATAAATCAGGAT & & \\
\hline \multirow[t]{2}{*}{ Rickettsia spp./ompA } & $\operatorname{Rr} 190.70$ & ATGGCGAATATTTCTCCAAAA & \multirow[t]{2}{*}{532} & \multirow[t]{2}{*}{ [24] } \\
\hline & $\operatorname{Rr} 190.701$ & GTTCCGTTAATGGCAGCATCT & & \\
\hline
\end{tabular}

gltA Rickettsial citrate synthase-encoding gene, ompA rickettsial outer membrane protein $\mathrm{A}$

a These primers were used in a real-time PCR assay with the following internal probe: 5' 6-FAM CAT TGT GCC ATC CAG CCT ACG GT- BHQ-1 3 '

genomic DNA, $1 \mu \mathrm{l}$ of each primer, $8.5 \mu \mathrm{l}$ PCR water and $12.5 \mu \mathrm{l}$ master mix; Thermo Fisher Scientific). PCR cycling parameters were as previously reported [2, 22, 24] (see Table 1). PCR products were electrophoresed in $1.5 \%$ agarose gels, and the results were captured with GelDoc (UVP BioDoc-It imaging system; Analytik Jena AG, Jena, Germany). Amplicons of the expected size were purified with ExoSAP-IT (Thermo Fisher Scientific) and sequenced using the BigDye Terminator v3.1 Cycle Sequencing Kit (Applied Biosystems, Thermo Fisher Scientific) in an ABI 3500 Genetic Analyzer automated device (Applied Biosystems, Thermo Fisher Scientific).

\section{Sequence and phylogenetic analyses}

The obtained sequences were assembled and trimmed in SeqMan v 5.00 (DNASTAR, Madison, WI, USA) and subjected to BLASTn analyses (www.ncbi.nlm.nih.gov/ blast) to infer closest identities with the organisms available in GenBank [25]. Alignments with our sequences and GenBank-retrieved sequences were constructed with CLUSTAL W in BioEdit [26, 27] manually edited with GeneDoc [28]. A phylogenetic tree for the tick mitochondrial 16S rRNA gene was implemented in MEGA X [29] and constructed using the neighbor-joining method with 1000 bootstrap replicons [30]. For alignment of the ompA rickettsial gene, we constructed a phylogenetic tree in MrBayes using Bayesian statistics [31], with four independent Markov chain runs for 1,000,000 metropolis-coupled Markov chain Monte Carlo (MCMC) generations, sampling a tree every 100th generation. The first $25 \%$ of the trees represented burn-in, and the remaining trees were used to calculate the Bayesian posterior probability.

\section{Statistical analysis}

The recorded observations were assembled and arranged in the spreadsheets of Microsoft Excel V 2016. The chisquare test $\left(\mathrm{X}^{2}\right)$ was used for differences, and relative risk
(RR) was analyzed using GraphPad Prism v. 5.00 (GraphPad Software Inc., San Diego, CA, USA), with the 95\% confidence interval (CI). Significance was set at $P<0.05$.

\section{Results}

Demographic characteristics of the study population

A total of 404 animals were sampled, including 200 horses, 171 donkeys and 33 mules, of which 324 (80.2\%) were found to be infested with ticks (mean infestation 110.3, standard deviation [SD] 80.79, 95\% CI - 90.35311 ). Of the equids inspected, horses were the most infested $(161,85.5 \%)$ followed by donkeys $(145,80 \%)$ and mules $(18,55 \%)$. The highest tick burdens were found in equids inspected in Peshawar (103, 19\%), Mardan (101, $18 \%)$, Nowshera $(100,18 \%)$, Swabi $(96,12.5 \%)$ and Charsadda $(65,11 \%)$; the lowest burdens were observed in Upper Dir (11, 2\%), Malakand (22, 4\%), Bajaur (24, 4\%) and Buner (27, 5\%) (Fig. 1; Table 2). The geography of each collection point significantly influenced the pattern of tick infestation on the hosts $(P<0.002)$.

The trend line of tick infestation increased from May (61, 11\%) to August $(77,14 \%)$ of 2019 , with the highest tick infestation found to be throughout the summer $(P<0.0354)$ and the lowest tick infestation during the winter between November $(13,2.3 \%)$ and January $(6,1 \%)$ $(P=0.1907)$ (Fig. 2). Linear regression analysis showed a significant association between tick infestation and high humidity $\left(r^{2}=0.9006, P<0.0001\right)$ and temperature $\left(r^{2}=0.75827, P<0.0002\right)$.

\section{Ticks and equid populations}

A total of 550 collected ticks were morphologically identified into two genera and five species as follows: Rhipicephalus (539 specimens, $98 \%$ of all ticks) and Hyalomma (11, 2\%). The most numerous tick species was Rhipicephalus microplus (341 specimens, 62\%) followed by $R h$. haemaphysaloides (126, 23\%), Rh. turanicus (39, 7\%), Rh. 
Table 2 Ticks collected from equids in selected districts of Khyber Pakhtunkhwa, Pakistan, between November 2018 and October 2019

\begin{tabular}{|c|c|c|c|c|c|}
\hline Districts & Tick species & $\begin{array}{l}\text { Total no. collected } \\
\text { ticks }\end{array}$ & $\begin{array}{l}\text { Ticks processed for } \\
\text { molecular analyses }\end{array}$ & $\begin{array}{l}\text { No. of ticks yielding } \\
\text { rickettsial DNA }\end{array}$ & $\begin{array}{l}\text { Host infested with } \\
\text { Rickettsia-positive } \\
\text { ticks }\end{array}$ \\
\hline Upper Dir & Rhipicephalus. microplus & 11 & $4 \mathrm{~N}, 1 \mathrm{M}, 3 \mathrm{~F}$ & $1 \mathrm{~N}$ & Mule \\
\hline \multirow[t]{2}{*}{ Bajaur } & Rh. haemaphysaloides & 17 & $3 \mathrm{~N}, 1 \mathrm{M}, 2 \mathrm{~F}$ & $1 \mathrm{~N}$ & Horse \\
\hline & Rh. microplus & 07 & $2 \mathrm{~N}, 1 \mathrm{~F}$ & $1 \mathrm{~N}$ & \\
\hline \multirow[t]{4}{*}{ Mardan } & Rh. haemaphysaloides & 51 & $2 \mathrm{~N}, 1 \mathrm{~F}$ & $1 \mathrm{~N}$ & Horse \\
\hline & Rh. microplus & 8 & $2 \mathrm{~N}, 1 \mathrm{~F}$ & $1 \mathrm{~N}$ & \\
\hline & Rh. turanicus & 9 & $1 \mathrm{~N}, 1 \mathrm{~F}$ & & \\
\hline & Rh. sanguineus & 33 & $3 \mathrm{~N}, 1 \mathrm{M}, 2 \mathrm{~F}$ & & \\
\hline \multirow[t]{2}{*}{ Peshawar } & Rh. microplus & 92 & $3 \mathrm{~N}, 3 \mathrm{~F}$ & $2 N^{b}$ & Donkey \\
\hline & Hyalomma anatolicum & 11 & $3 \mathrm{~N}, 1 \mathrm{M}, 3 \mathrm{~F}$ & & \\
\hline \multirow[t]{2}{*}{ Charsadda } & Rh. haemaphysaloides & 85 & $3 \mathrm{~N}, 2 \mathrm{~F}$ & $1 \mathrm{~N}$ & Horse \\
\hline & Rh. microplus & 10 & $2 \mathrm{~N}, 1 \mathrm{M}, 1 \mathrm{~F}$ & $1 \mathrm{~N}$ & \\
\hline \multirow[t]{2}{*}{ Malakand } & Rh. microplus & 17 & $1 \mathrm{~N}, 1 \mathrm{~F}$ & $1 \mathrm{~N}$ & Horse \\
\hline & Rh. turanicus & 3 & $2 \mathrm{~N}, 1 \mathrm{M}, 1 \mathrm{~F}$ & & \\
\hline \multirow[t]{2}{*}{ Swabi } & Rh. microplus & 82 & $2 \mathrm{~N}, 1 \mathrm{~F}$ & $1 \mathrm{~F}$ & Horse \\
\hline & Rh. turanicus & 14 & $3 \mathrm{~N}, 1 \mathrm{M}, 2 \mathrm{~F}$ & & \\
\hline \multirow[t]{2}{*}{ Nowshera } & Rh. microplus & 87 & $2 \mathrm{~N}, 3 \mathrm{~F}$ & $1 \mathrm{~N}$ & Mule \\
\hline & Rh. turanicus & 13 & $2 \mathrm{~N}, 1 \mathrm{M}, 3 \mathrm{~F}$ & & \\
\hline \multirow[t]{2}{*}{ Buner } & Rh. microplus & 27 & $6 \mathrm{~N}, 1 \mathrm{M}, 5 \mathrm{~F}$ & $1 \mathrm{~F}$ & Donkey \\
\hline & Total & 550 & $91(46 \mathrm{~N}, 9 \mathrm{M}, 36 \mathrm{~F})$ & $13(14 \%)$ & \\
\hline
\end{tabular}

a PCR assays targeting the tick $16 \mathrm{~S}$ rRNA gene and the rickettsial $g / t A$, and ompA gene; $N$ nymphs, $M$ males, $F$ females

${ }^{b}$ Both nymphs of Rh. microplus were from the same donkey

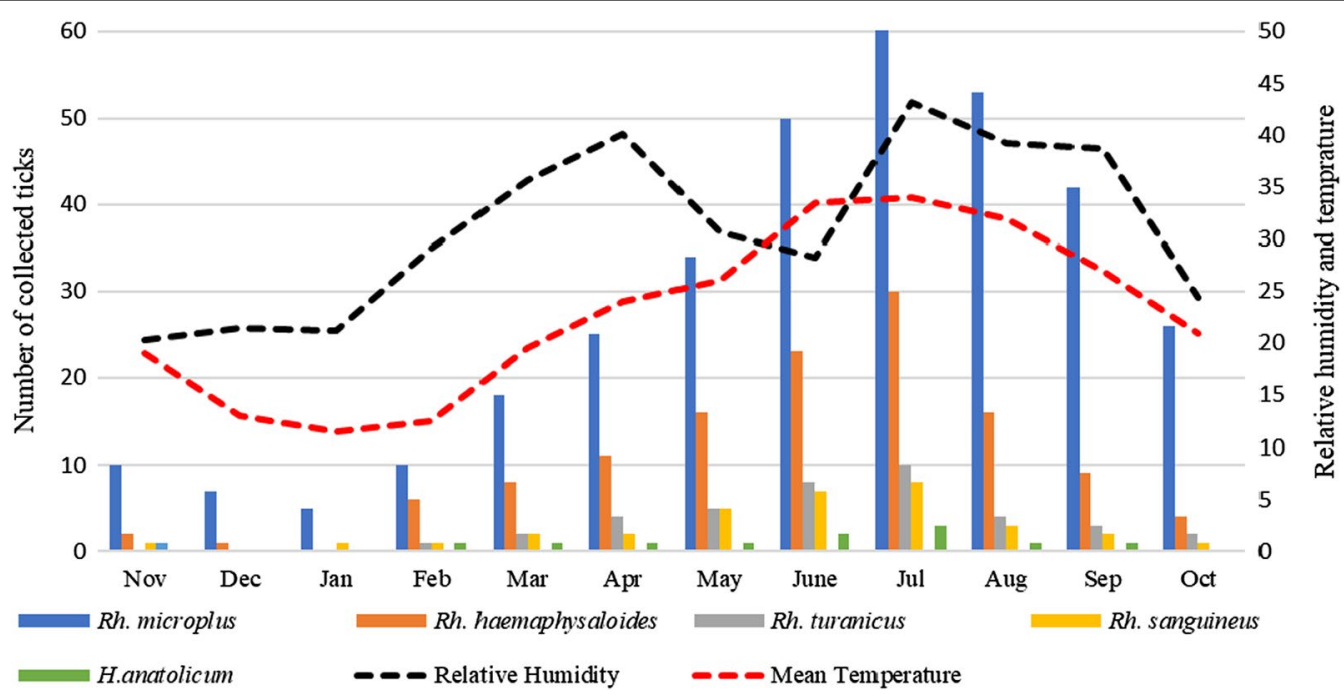

Fig. 2 Temporal distribution of tick species collected during this study

sanguineus (s.l.) (33, 6\%) and Hyalomma anatolicum (11, $2 \%)$.

A total of 263 ticks (48\% of all collected ticks) were collected from horses, of which 185 were $R h$. microplus $(70 \%$ of the ticks from horses), 44 were $R h$. haemaphysaloides
(17\%), 18 were $R h$. turanicus $(0.06 \%)$, ten were $R h$. sanguineus (s.l.) (0.03\%) and six were H. anatolicum (0.03\%). From donkeys, 206 ticks (37\% of all collected ticks) were collected, of which 110 were $R h$. microplus (53\% of the ticks from donkeys), 62 were $R h$. haemaphysaloides 
(30\%), 13 were $R h$. turanicus (06\%), 18 were $R h$. sanguineus (s.l.) (8\%) and three were H. anatolicum (1\%). Mules were infested by 81 tick specimens (15\% of all collected ticks), of which 46 were $R h$. microplus (57\% of the ticks from mules), 20 were $R h$. haemaphysaloides (24\%), eight were $R h$. turanicus (10\%), five were $R h$. sanguineus (s.l.) (6\%) and two were H. anatolicum (2\%) (Table 3).

\section{Tick infestation on different body parts of the equid host}

Different parts of the body of the equid hosts were examined for ticks. The highest infestations were observed on the axial region of horses $(63,24 \%)$, the sternum of donkeys $(44,21 \%)$ and the belly of mules $(19,23 \%)$. The lowest tick-infested body parts were the dewlap in horses $(37,14 \%)$, the axial region in donkeys $(25,12 \%)$ and the scrotum of mules $(10,12 \%)$. Statistical analysis of infestation of the body regions of the equid hosts revealed significant differences $\left(\chi^{2}=18.66,10 ; P<0.045\right)$ (Table 4).

\section{Assessment of risk factors associated with tick infestations} Several independent variables (Table 5) potentially associated with tick infestations on equids were analyzed and the risk factors calculated. Analysis of infestation according to sex revealed that there were more tick infestations on male equids than on female equids, with the difference being statistically significant in the tick acquisition. When age was considered, the highest tick infestation was found on adult hosts aged 4-6 years compared to hosts aged 1-3 years. Most of the equids examined were in the plain areas, but tick infestations were predominantly found on equids in hilly areas, and the association between a high risk of tick infestation and equids in hilly areas was significant. When animal housing was considered, the tick infestation rate was found to be higher on equids in muddy systems than those maintained in concrete and semi-concrete housing. The risk of tick infestation was also higher in those managed in mud housing than in those in open grazing systems. Equids raised in a herd were found to have a higher risk of tick infestation than those reared solely. Providing fresh or stored food to the equids had no impact on the tick infestations (Table 5).

Molecular confirmation of taxonomic identification of ticks Partial sequences of the tick mitochondrial 16S rRNA gene were successfully obtained from $R h$. microplus (56 specimens), Rh. turanicus (15 specimens), Rh. sanguineus (s.l.) (2 specimens), Rh. haemaphysaloides (12 specimens) and $H$. anatolicum (5 specimens). BLAST of obtained $16 \mathrm{~S}$ rRNA sequences for $R h$. microplus, $R h$. haemaphysaloides and $H$. anatolicum resulted in the screening of homologous sequences from Pakistan, India and China that showed $98-99 \%$ identity. The BLAST of Rh. turanicus showed closest identity (95-97\%) with conspecific sequences reported from India, Afghanistan, Iran, South Africa and China, and the Rh. sanguineus (s.l.) sequences showed highest identities (96-98\%) with conspecific sequences from Taiwan, USA and Singapore.

Table 3 Tick stages and species collected across Khyber Pakhtunkhwa, Pakistan, from equids

\begin{tabular}{|c|c|c|c|c|c|c|}
\hline Tick species & Horse (N/M/F) & Donkey (N/M/F) & Mule (N/M/F) & Total (\%) & Mean (SD) & $P$ value $\left(X^{2}\right)$ \\
\hline Rh. microplus & 29/65/91 & $16 / 36 / 58$ & $7 / 14 / 25$ & $341(62)$ & $113.7(69.57)$ & $0.0041(15.32,4)$ \\
\hline Rh. haemaphysaloides & $10 / 14 / 20$ & $11 / 21 / 30$ & $3 / 6 / 11$ & $126(23)$ & $38.67(21.3)$ & \\
\hline Rh. turanicus & $2 / 6 / 10$ & $0 / 4 / 9$ & $1 / 4 / 3$ & $39(7)$ & $16.33(10.41)$ & \\
\hline Rh. sanguineus & $1 / 3 / 6$ & $4 / 6 / 8$ & $0 / 2 / 3$ & $33(6)$ & $11.00(6.557)$ & \\
\hline H. anatolicum & $1 / 3 / 2$ & $0 / 2 / 1$ & $0 / 0 / 2$ & $11(2)$ & $4.333(1.528)$ & \\
\hline
\end{tabular}

Values in table are presented as a number unless indicated otherwise

$F$ Female, $M$ male, $N$ nymph, $S D$ standard deviation

Table 4 Number of ticks collected from different body parts of the equid hosts

\begin{tabular}{|c|c|c|c|c|c|c|}
\hline Infested body parts & Horse, $n(\%)$ & Donkey, n (\%) & Mule, $n(\%)$ & Total, $n$ (\%) & Mean (SD) & $P$ value $\left(X^{2}\right)$ \\
\hline Dewlap & $37(14)$ & $39(19)$ & $15(19)$ & $91(17)$ & $30.33(13.32)$ & $0.045(18.66,10)$ \\
\hline Belly & $39(15)$ & $34(17)$ & $19(23)$ & $90(16)$ & $30(11.5)$ & \\
\hline Sternum & $38(14)$ & $44(21)$ & $11(14)$ & $93(17)$ & $31(17.58)$ & \\
\hline Udder & $46(17)$ & $33(16)$ & $12(15)$ & $91(17)$ & $30.33(17.16)$ & \\
\hline Axial region & $63(24)$ & $25(12)$ & $14(17)$ & $107(19)$ & $35.67(23.86)$ & \\
\hline Scrotum & $40(15)$ & $31(15)$ & $10(12)$ & $78(14)$ & $26(17.06)$ & \\
\hline Total & $263(48)$ & $206(37)$ & $81(15)$ & $550(100)$ & $183.3(93.09)$ & \\
\hline
\end{tabular}


Table 5 Risk factors associated with tick infestation on equid hosts

\begin{tabular}{|c|c|c|c|c|c|c|}
\hline Variables & Condition & $\begin{array}{l}\text { No. examined } \\
\text { equids }\end{array}$ & $\begin{array}{l}\text { No of tick-infested } \\
\text { equids (\%) }\end{array}$ & Mean (SD) & $\begin{array}{l}\text { Relative risk ( } 95 \% \\
\text { confidence interval) }\end{array}$ & $P$ value $\left(X^{2}\right)$ \\
\hline \multirow[t]{2}{*}{ Gender } & Male & 330 & $294(91)$ & $312.0(25.46)$ & $0.7432(0.64-0.85)$ & $0.001(12.05,1)$ \\
\hline & Female & 74 & $30(9)$ & $52.00(31.11)$ & & \\
\hline \multirow[t]{2}{*}{ Age groups (years) } & $1-3$ & 100 & $50(15)$ & $75.00(35.36)$ & $1.268(1.10-1.45)$ & $0.002(9.548,1)$ \\
\hline & $4-6$ & 304 & $274(85)$ & $289.0(21.21)$ & & \\
\hline \multirow[t]{2}{*}{ Altitude } & Hilly areas & 140 & $140(43)$ & $143.5(4.950)$ & $0.8485(0.73-0.97)$ & $0.02(5.562,1)$ \\
\hline & Plain areas & 264 & $184(57)$ & $220.5(51.62)$ & & \\
\hline \multirow[t]{3}{*}{ Housing } & Mud & 213 & $203(63)$ & $208.0(7.071)$ & - & - \\
\hline & Concrete & 56 & $38(11)$ & $38.00(25.46)$ & $0.6949(0.58-0.81)$ & $0.001(13.11,1)$ \\
\hline & Semi-concrete & 135 & $83(26)$ & $174.0(55.15)$ & $0.8268(0.71-0.95)$ & $0.01(6.645,1)$ \\
\hline \multirow[t]{2}{*}{ Grazing } & Open & 246 & $229(71)$ & $237.5(12.02)$ & $0.8293(0.72-0.94)$ & $0.01(7.597,1)$ \\
\hline & Domesticated & 158 & $95(29)$ & $126.5(44.55)$ & & \\
\hline \multirow[t]{2}{*}{ Living management } & Single & 115 & $63(19)$ & $89.00(36.77)$ & $1.230(1.07-1.40)$ & $0.01(7.921,1)$ \\
\hline & Herd & 289 & $261(81)$ & $275.0(19.80)$ & & \\
\hline \multirow[t]{2}{*}{ Food supply } & Fresh & 295 & $238(73)$ & $266.5(40.31)$ & $0.9902(0.85-1.14)$ & $0.9(0.0171,1)$ \\
\hline & Stored & 109 & $86(27)$ & $97.50(16.26)$ & & \\
\hline
\end{tabular}

The resultant consensus sequences after trimming were deposited in the GenBank for each species; $R h$. microplus (accession MW071171), Rh. turanicus (MW074299), Rh. sanguineus (s.l.) (MW113239), Rh. haemaphysaloides (MW113238) and H. anatolicum (MW172215). The phylogenetic analysis of the collected five species revealed an evolutionary relatedness with homologous species reported in Pakistan's neighboring countries. In a phylogenetic tree, the obtained sequences of prevalent tick species clustered with the same species reported in the bordering countries (Fig. 3).

\section{Detection of rickettsial DNA in ticks}

The DNA of 91 tick specimens were molecularly tested by real-time PCR, which detected rickettsial DNA in 23 specimens of ticks ( $R h$. microplus, Rh. turanicus, $R h$. haemaphysaloides and $H$. anatolicum). Among these, ten speciments showed high $\mathrm{Cq}$ values (>35) and were excluded from further analyses. The remaining 13 samples were found to be positive for Rickettsia through conventional PCR targeting the rickettsial gltA and ompA genes. These Rickettsia-positive ticks included Rh. microplus-infected ticks (10/91, 11\%) from all sampled districts, and $R h$. haemaphysaloides-infected ticks (3/91, 3\%) from Bajaur, Mardan and Charsadda districts. No Rickettsia spp. were detected in Rh. turanicus, Rh. sanguineus (s.l.) and $H$. anatolicum through PCR. A consensus partial sequence (333 bp) of the highly conserved Rickettsia gltA gene, detected in Rh. microplus and $R h$. haemaphysaloides, was $100 \%$ identical to several sequences of $R$. massiliae from GenBank (MF002497, KY069259, KT588058, МТ309038, MT309037,
JN043507, CP000683, U59719). From these same ticks, a consensus partial sequence (592 bp) of the highly polymorphic Rickettsia ompA gene was $100 \%$ identical to a sequence of $R$. massiliae from GenBank (CP003319). The obtained sequences of $g l t A$ and $\operatorname{omp} A$ were uploaded to GenBank with accessions numbers MW922872 and MW928497 respectively. The obtained sequence of the ompA gene for Rickettsia spp. clustered with sequences of $R$. massiliae in a phylogenetic tree (Fig. 4).

\section{Discussion}

Ecological changes and an increasingly evident increase in global temperature have widely impacted the distribution of ticks and tick-borne diseases, ultimately increasing their threat to public and veterinary health $[9,10]$. Based on spatial distribution and molecular evidence, it has been suggested that global climate change has played a significant role in the spread of tick species [10]. Previously, we reported numerous tick species infesting diverse hosts, including equids (horse), in selected districts of KP, Pakistan [13, 17]. However, a knowledge gap remained on the identity and effect of various factors affecting ticks infesting equid hosts and their associated Rickettsia spp. To fill this gap, we designed this study to investigate equid hosts for tick infestation, associated risk factors and the molecular phylogeny of these ticks in selected districts of KP, Pakistan. The collected ticks from five selected districts were categorized into two genera which included five medically important tick species: Rh. microplus, $R h$. haemaphysaloides, $R h$. turanicus, Rh. sanguineus (s.l.) and H. anatolicum. These ticks were found to be infesting equid hosts (horses, mules, 


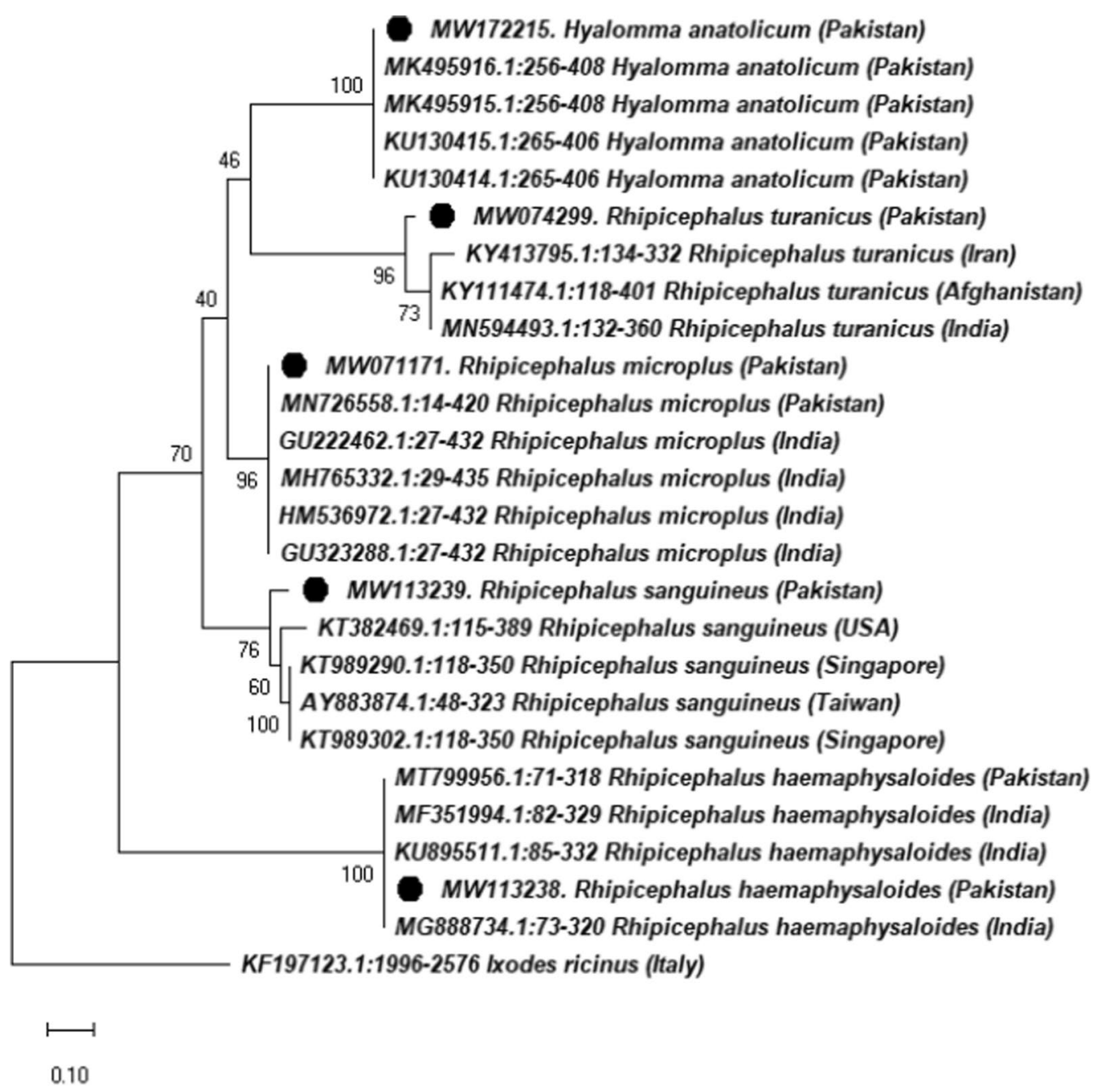

Fig. 3 Phylogenetic analysis based on 16S rRNA gene partial sequences of Rhipicephalus species and Hyalomma anatolicum from Pakistan using neighbor-joining method in Mega X. Accession numbers are followed by species and country names. The bootstrap values are shown at each node (1000). The bar represents 0.1 substitutions per site. Sequences obtained in the present study are denoted with black circles

donkeys) throughout the year in extreme cool to extreme hot weather conditions. The bacterium Rickettsia massiliae was detected in all $R h$. microplus ticks collected in all nine study districts and in Rh. haemaphysaloides collected in Bajaur, Mardan and Charsadda districts. Ecological conditions and biotopes drive the geographic distribution and the risks associated with the possible harmful effects of tick species. The favorable environmental conditions in the region extend tick adaptation and also result in infestation of novel hosts [13, 16, 17].

Risk factors, such as age, altitude, housing type, grazing, living management and food conditions, of equid hosts with respect to tick infestation were statistically significant, with the exception of food conditions. A strong correlation was observed between the intensity of tick infestation and temperature and relative humidity, with the highest infestation recorded in the summer (JuneAugust) and lowest infestation recorded in the winter (December-January); these results agree with previous reports in the region [16, 17, 32]. The variable climatic conditions of the KP favor tick survival and reproduction, resulting in high infestations on various hosts $[17,33]$.

The younger age group (1-years) of equid hosts was found to have lower tick infestations, possibly correlated with a strong immune response, shorter exposure to questing ticks, shorter time in free grazing conditions and frequent grooming, all of which protect younger equids from tick infestation [34-36]. Higher tick infestations on adult hosts may be due to the larger surface area of the body, which enhances the chances 


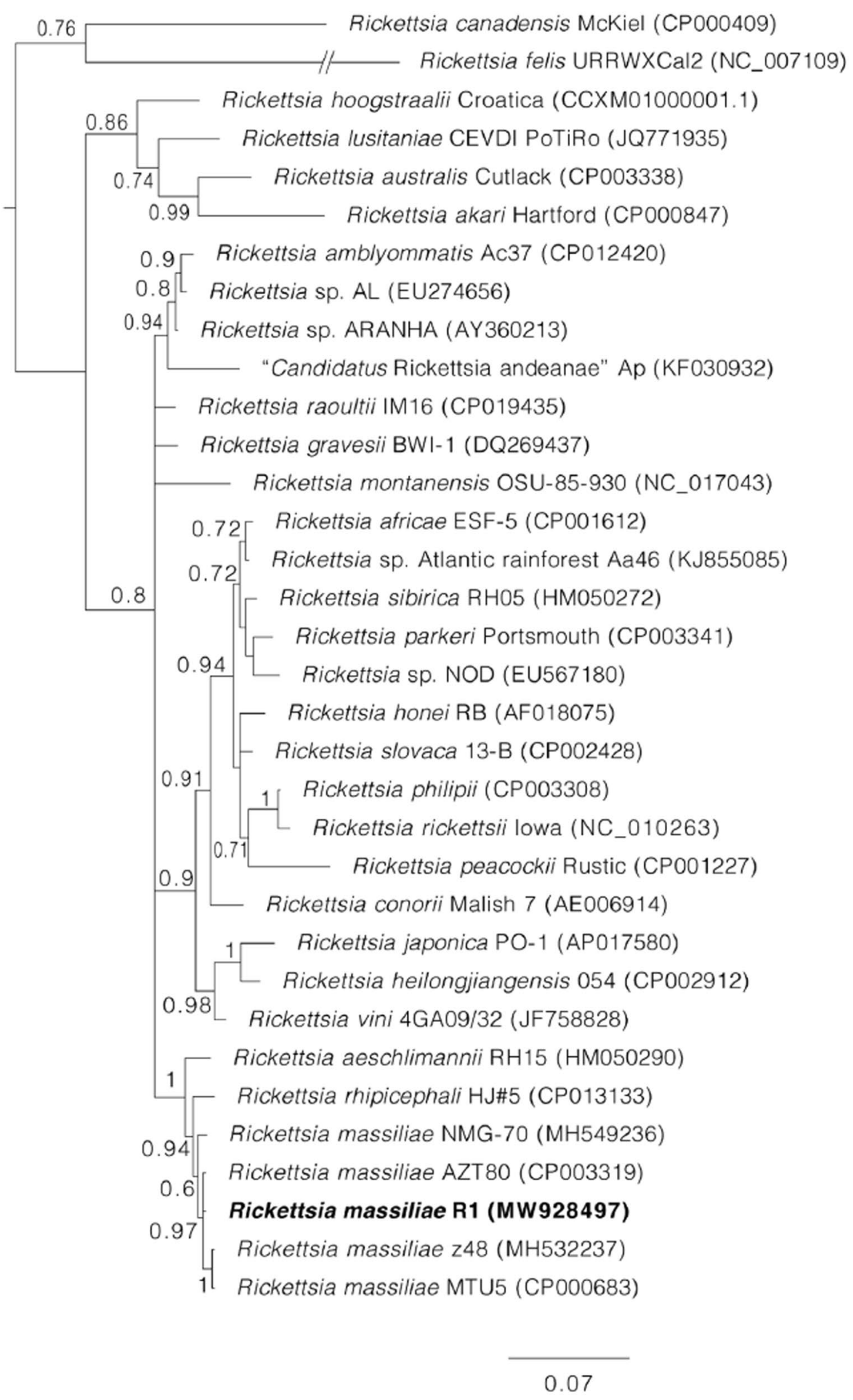

Fig. 4 Bayesian phylogenetic tree inferred from partial sequences of the rickettsial outer membrane protein A (ompA) gene of Rickettsia spp. The tree is drawn to scale with the scale bar indicating nucleotide substitutions per site. Values of Bayesian posterior probabilities are indicated above or below each branch. The sequence of Rickettsia massiliae detected in ticks from Pakistan is highlighted in bold 
of tick attachment, frequent use and ultimate resistance to acaricide and low immunity [32, 36-38]. The muddykeeping system of hosts provided favorable conditions for the survival and reproduction of ticks, as compared to concrete and semi-concrete keeping systems. Host density in herds ultimately increases the chances of tick infestation, compared to animals kept alone, due to the availability of host-questing ticks detached in the herd area [39-41]. Pastures with long grasses in the hilly areas may provide favorable conditions for the questing ticks where they await and attach to open-grazing equids.

Ticks collected across the different study regions belonged to two genera and five species. The most prevalent tick was Rh. microplus, which has been reported to the dominant tick species in the region [13, 16, 17]. The highest numbers of ticks were collected in the months of June to August, while the lowest numbers were collected in the coldest months of November to January, which is in accordance with the results of a previous study [17]. It is important to mention that several Haemaphysalis and Hyalomma species other than $H$. anatolicum are also abundant tick species in Pakistan [13, 16, 17], but these latter species were not found to infest the equids inspected in this study throughout the study period, possibly due to the availability of other suitable and accessible hosts for blood feeding. Several markers have been utilized to delineate the accurate identity of a tick species at the molecular level. For example, 16S rRNA, COX1, $12 \mathrm{~S}$ rRNA and ITS are well-known genetic markers that have been implied to separate closely related tick species $[17,42-44,51]$. Since the objective of this work was only to identify tick species-and not population structurewe used 16S rRNA to identify the collected tick species and to establish their evolutionary relationship [43-46]. The phylogenetic analysis of the collected ticks showed the closest relation with the same species reported from other countries, including Afghanistan, China, South Africa and Taiwan.

Tick-borne Rickettsia spp. have been collected from several Rhipicephalus ticks infesting different hosts in various regions of the world [13, 47-51]. In Pakistan, reports are not available on ticks infesting equids associated with Rickettsia infection. In this study, Rickettsia massiliae was detected in Rh. microplus and Rh. haemaphysaloides using gltA and ompA rickettsial markers. There have been several reports of spotted fever due to R. massiliae in Europe [49]. Noteworthy, this is the first report of $R$. massiliae associated with equid ticks in Pakistan. Our findings highlight that human illness due to this spotted fever group of pathogens could be underreported in Pakistan, where to date tick-borne rickettsioses have not been reported.

\section{Conclusions}

To our knowledge this is the first report of equid ticks from selected regions of KP. The risk factor analyses showed that temperature, humidity, age, keeping and grazing systems, sex and host species considerably affected the intensity of tick infestations. The phylogenetic tree of the collected ticks based on the tick mitochondrial $16 \mathrm{~S}$ rRNA gene (2 genera and 5 species) revealed a close resemblance to tick species reported from Afghanistan, China, South Africa and Taiwan. The human pathogen $R$. massiliae, a tick-borne pathogenic spotted fever group Rickettsia species, was detected in $R h$. microplus and Rh. haemaphysaloides. These results demonstrate that it is important to investigate the vector potential of ticks for other pathogens infesting equids in different regions of Pakistan to avoid the emergence of zoonotic infections. They will also provide valuable data for use in developing integrated control management strategies against ticks and tick-borne diseases in Pakistan.

\section{Acknowledgements \\ We acknowledge the partial financial support provided by the Pakistan Sci- ence Foundation and the Higher Education Commission of Pakistan.}

\section{Authors' contributions}

$A A, S M L, A S A$ and $M B L$ designed the study and acquired financing. AA, HZ, IZ, MT, SK, MH, MT, BA and MH collected the samples. IZ, HZ and ASA carried out the statistical analysis. AA, HZ, IZ, MT, SK, MH, MT, BA and MH, SML and MBL conducted the experiments. AA, HZ, IZ, ASA, SML and MBL contributed to the revision of critically important intellectual contents and manuscript writing. All authors carried out critical revisions. All authors read and approved the final manuscript.

\section{Funding}

Not applicable.

Availability of data and materials

The datasets supporting the conclusions of this article are included within the article.

\section{Declarations}

Ethics approval and consent to participate

Ethical consent was obtained from the advanced studies and research board of the Abdul Wali Khan University Mardan. Oral/written consent was obtained from the owner of equids for the collection of ticks and data such as hostrelated information (gender and age), eco-geography and herd management.

\section{Consent for publication}

Not applicable.

\section{Competing interests}

The authors declare that the research was conducted in the absence of any commercial or financial relationships that could be construed as a potential conflict of interest.

\section{Author details}

${ }^{1}$ Department of Zoology, Abdul Wali Khan University Mardan, Khyber Pakhtunkhwa, Pakistan. ${ }^{2}$ King Abdulaziz City for Science and Technology, Riyadh, Saudi Arabia. ${ }^{3}$ Departamento de Ciencia Animal, Facultad de Ciencias Veterinarias, Universidad de Concepción, Av. Vicente Méndez 595, casilla 537, Chillán, Nuble, Chile. ${ }^{4}$ Department of Preventive Veterinary Medicine 
and Animal Health, Faculty of Veterinary Medicine, University of São Paulo, São Paulo, Brazil.

\section{Received: 29 April 2021 Accepted: 9 June 2021}

Published online: 13 July 2021

\section{References}

1. Lew-Tabor AE, Rodriguez Valle MA. A review of reverse vaccinology approaches for the development of vaccines against ticks and tick borne diseases. Ticks Tick Borne Dis. 2016;7:573-85.

2. Labruna MB, Whitworth T, Bouyer DH, McBride J, Camargo LMA, Camargo EP, et al. Rickettsia bellii and Rickettsia amblyommii in Amblyomma ticks from the State of Rondonia. Western Amazon Brazil J Med Entomol. 2004;41:1073-81.

3. Gondard M, Cabezas-Cruz A, Charles RA, Vayssier-Taussat M, Albina E, Moutailler S. Ticks and tick-borne pathogens of the Caribbean: current understanding and future directions for more comprehensive surveillance. Front Cell Infect Microbiol. 2017;7:1-16.

4. Schorderet-Weber S, Noack S, Selzer PM, Kaminsky R. Blocking transmission of vector-borne diseases. Int J Parasitol-Drug. 2017;7:90-109.

5. Estrada-Peña A, Ayllón N, De La Fuente J. Impact of climate trends on tickborne pathogen transmission. Front Physiol. 2012;3:1-12.

6. Szabó MPJ, Pinter A, Labruna MB. Ecology, biology and distribution of spotted-fever tick vectors in Brazil. Front Cell Infect Microbiol. 2013;3:1-9.

7. Esser HJ, Mögling R, Cleton NB, Van Der Jeugd H, Sprong H, Stroo A, et al. Risk factors associated with sustained circulation of six zoonotic arboviruses: a systematic review for selection of surveillance sites in nonendemic areas. Parasit Vectors. 2019;12:1-17.

8. Pietzsch ME, Medlock JM, Jones L, Avenell D, Abbott J, Harding P, et al. Distribution of Ixodes ricinus in the British Isles: investigation of historical records. Med Vet Entomol. 2005;19:306-14.

9. Leger E, Vourch G, Vial L, Chevillon C, McCoy KD. Changing distributions of ticks: causes and consequences. Exp Appl Acarol. 2013;59:219-44.

10. Estrada-Peña A. Climate, niche, ticks, and models: what they are and how we should interpret them. Parasitol Res. 2008;103:87-95.

11. Egekwu N, Sonenshine DE, Bissinger BW, Roe RM. Transcriptome of the female synganglion of the black-legged tick Ixodes scapularis (Acari: Ixodidae) with comparison between Illumina and 454 systems. PLoS ONE. 2014;9(7):1-24.

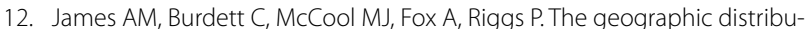
tion and ecological preferences of the American dog tick, Dermacentor variabilis (Say), in the USA. Med Vet Entomol. 2015;29(2):178-88.

13. Karim S, Budachetri K, Mukherjee N, Williams J, Kausar A, Hassan MJ, et al. A study of ticks and tick-borne livestock pathogens in Pakistan. PLOS Negl Trop Dis. 2017;11(6):1-17.

14. Laus F, Veronesi F, Passamonti F, Paggi E, Cerquetella M, Hyatt D, et al. Prevalence of tick-borne pathogens in horses from Italy. J Vet Med Sci. 2013;75(6):715-20.

15. Kamran K, Ali A, Villagra C, Siddiqui S, Alouffi AS, lqbal A. A cross-sectional study of hard ticks (Acari: Ixodidae) on horse farms to assess the risk factors associated with tick-borne diseases. Zoonoses Public Health. 2021;68(3):247-62.

16. Rehman A, Nijhof AM, Sauter-Louism C, Schauer B, Staubach C, Conraths FJ. Distribution of ticks infesting ruminants and risk factors associated with high tick prevalence in livestock farms in the semi-arid and arid agro-ecological zones of Pakistan. Parasites Vectors. 2017;10(1):1-15.

17. Ali A, Khan MA, Zahid H, Yaseen PM, Khan MQ, Nawab J, et al. Seasonal dynamics, record of ticks infesting humans, wild and domestic animals and molecular phylogeny of Rhipicephalus microplus in Khyber Pakhtunkhwa Pakistan. Front Physiol. 2019;10:1-15.

18. Geevarghese G, Dhanda V. The Indian Hyalomma ticks (Ixodoidea: Ixodidae). New Delhi: ICAR Press; 1987. p. 119.

19. Walker JB, Keirans JE, Horak IG. The genus Rhipicephalus (Acari, Ixodidae) a guide to the brown ticks of the world. Cambridge: Cambridge University Press; 2005.

20. Sambrook J, Russell DW. Molecular cloning: a laboratory manual. New York: Cold Spring Harbor Laboratory Press; 2001. p. 23-44.
21. Sangioni LA, Horta MC, Vianna MC, Gennari SM, Soares RM, Galvão MA, et al. Rickettsial Infection in animals and Brazilian spotted fever endemicity. Emerg Infect Dis. 2005;11:265-70.

22. Mangold AJ, Bargues MD, Mas-Coma S. Mitochondrial 165 rDNA sequences and phylogenetic relationships of species of Rhipicephalus and other tick genera among Metastriata (Acari: Ixodidae). Parasitol Res. 1998;84:478-84.

23. Regnery RL, Spruill CL, Plikaytis BD. Genotypic identification of rickettsiae and estimation of intraspecies sequence divergence for portions of two rickettsial genes. J Bacteriol. 1991;173(5):1576-89.

24. Roux V, Fournier PE, Raoult D. Differentiation of spotted fever group rickettsiae by sequencing and analysis of restriction fragment length polymorphism of PCR-amplified DNA of the gene encoding the protein rOmpA. J Clin Microbiol. 1996;34:2058-65.

25. Altschul SF, Gish W, Miller W, Myers EW, Lipman DJ. Basic local alignment search tool. J Mol Biol. 1990;215(3):403-10.

26. Thompson JD, Higgins DG, Gibson TJ. CLUSTAL W: improving the sensitivity of progressive multiple sequence alignment through sequence weighting, position-specific gap penalties and weight matrix choice. Nucleic Acids Res. 1994;22(22):4673-80.

27. Hall T, Biosciences I, Carlsbad C. BioEdit: an important software for molecular biology. GERF Bull Biosci. 2011;2:60-1.

28. Nicholas KB. GeneDoc: analysis and visualization of genetic variation. EMBNEW News. 1997:4:14.

29. Kumar S, Stecher G, Li M, Knyaz C, Tamura KMEGAX. molecular evolutionary genetics analysis across computing platforms. Mol Biol Evol. 2018;35(6):1547-9.

30. Tamura K, Stecher G, Peterson D, Filipski A, Kumar S. MEGA6: molecular evolutionary genetics analysis version 6.0. Mol Biol Evol. 2013;30(12):2725-9.

31. Huelsenbeck JP, Ronquist F. MRBAYES: Bayesian inference of phylogenetic trees. Bioinformatics. 2001;17:754-5.

32. Kamran K, Ali A, Villagra AC, Bazai ZA, lqbal A, Sajid MS. Hyalomma anatolicum resistance against ivermectin and fipronil is associated with indiscriminate use of acaricides in southwestern Balochistan. Pakistan Parasitol Res. 2020;120:1-25.

33. Zahid H, Munoz-Leal S, Khan MK, Alouffi A, Labruna MB, Ali A. Life cycle and genetic identification of Argas persicus infesting domestic fowl in Khyber Pakhtunkhwa. Pakistan Front Vet Sci. 2021;8:1-10.

34. Swai ES, Mbise AN, Kessy V, Kaaya E, Sanka P, Loomu PM. Farm constraints, cattle disease perception and tick management practices in pastoral Maasai community-Ngorongoro. Tanzania Livest Res Rural Dev. 2005; 17(2):17-20.

35. Mooring $\mathrm{B}$, Harte $\mathrm{H}$. Testing the interspecific body size principle in ungulates: the smaller they come, the harder they groom. Anim Behav. 2000;60:35-45.

36. Lorusso V, Picozzi K, de Bronsvoort BM, Majekodunmi A, Dongkum C, Balak G, et al. Ixodid ticks of traditionally managed cattle in central Nigeria: where Rhipicephalus (Boophilus) microplus does not dare (yet?). Parasites Vectors. 2013;6:1-10.

37. Kemal J, Tamerat N, Tuluka T. Infestation and identification of ixodid tick in cattle: the case of Arbegona District Southern Ethiopia. J Vet Sci. 2016;5:1-8.

38. Tabor AE, Ali A, Rehman G, Rocha Garcia G, Zangirolamo AF, Malardo T, et al. Cattle tick Rhipicephalus microplus-host interface: a review of resistant and susceptible host responses. Front Cell Infect Microbiol. 2017;7:1-18.

39. Labruna MB, Kasai N, Ferreira F, Faccini JL, Gennari SM. Seasonal dynamics of ticks (Acari: Ixodidae) on horses in the state of São Paulo. Brazil Vet Parasitol. 2002;105(1):65-77.

40. Greenfield BPJ. Environmental parameters affecting tick (Ixodes ricinus) distribution during the summer season in Richmond Park. London Biosci Horiz. 2011;4(2):140-8.

41. Gharbi M, Moussi N, Jedidi M, Mhadhbi M, Sassi L, Darghouth MA. Population dynamics of ticks infesting the one-humped camel (Camelus dromedarius) in central Tunisia. Ticks Tick Borne Dis. 2013;4(6):488-91.

42. Burger TD, Shao R, Barker SC. Phylogenetic analysis of mitochondrial genome sequences indicates that the cattle tick, Rhipicephalus (Boophilus) microplus, contains a cryptic species. Mol Phylogenet Evol. 2014;76:241-53. 
43. Lv J, Wu S, Zhang Y, Chen Y, Feng C, Yuan X, et al. Assessment of four DNA fragments (COI, 16S rDNA, ITS2, 12S rDNA) for species identification of the Ixodida (Acari: Ixodida). Parasites Vectors. 2014;7(1):1-11.

44. Low VL, Tay ST, Kho KL, Koh FX, Tan TK, Lim YAL, et al. Molecular characterization of the tick Rhipicephalus microplus in Malaysia: new insights into the cryptic diversity and distinct genetic assemblages throughout the world. Parasit Vectors. 2015;8(1):1-10.

45. Ali A, Parizi LF, Ferreira BR, Junior $V$, Silva I. A revision of two distinct species of Rhipicephalus: R. microplus and R. australis. Cienc Rural. 2016;46:1240-8.

46. Roy BC, Estrada-Peña A, Krücken J, Rehman A, Nijhof AM. Morphological and phylogenetic analyses of Rhipicephalus microplus ticks from Bangladesh, Pakistan and Myanmar. Ticks Tick Borne Dis. 2018;9(5):1069-79.

47. Eremeeva ME, Zambrano ML, Anaya L, Beati L, Karpathy SE, Santos-Silva $\mathrm{MM}$, et al. Rickettsia rickettsii in ticks, Mexicali, Mexico. J Med Entomol. 2011:48(2):418-21.

48. Abarca K, López J, Acosta-Jamett G, Martínez-Valdebenito C. Rickettsia felis in Rhipicephalus sanguineus from two distant Chilean cities. Vector Borne Zoonotic Dis. 2013;13(8):607-9.
49. Parola P, Paddock CD, Socolovschi C, Labruna MB, Mediannikov O, KernifT, et al. Update on tick-borne rickettsioses around the world: a geographic approach. Clin Microbiol Rev. 2013;26(4):657-702.

50. Wei QQ, Guo LP, Wang AD, Mu LM, Zhang K, Chen CF, et al. The first detection of Rickettsia aeschlimannii and Rickettsia massiliae in Rhipicephalus turanicus ticks, in northwest China. Parasites Vectors. 2015;8(1):1-4.

51. Ortuño A, Sanfeliu I, Nogueras MM, Pons I, López-Claessens S, Castellà J, et al. Detection of Rickettsia massiliae/Bar29 and Rickettsia conorii in red foxes (Vulpes vulpes) and their Rhipicephalus sanguineus complex ticks. Ticks Tick Borne Dis. 2018;9(3):629-31.

\section{Publisher's Note}

Springer Nature remains neutral with regard to jurisdictional claims in published maps and institutional affiliations.
Ready to submit your research? Choose BMC and benefit from:

- fast, convenient online submission

- thorough peer review by experienced researchers in your field

- rapid publication on acceptance

- support for research data, including large and complex data types

- gold Open Access which fosters wider collaboration and increased citations

- maximum visibility for your research: over 100M website views per year

At BMC, research is always in progress.

Learn more biomedcentral.com/submissions 